\title{
University Students' Online Learning Self-efficacy and Self-regulated Learning during the COVID-19 Pandemic
}

\author{
Titik Ulfatun, Fitri Septiyanti, and Aprilia Garia Lesmana
}

\begin{abstract}
The teaching and learning process has shifted online since the outbreak of COVID-19 in Indonesia. Students have had to adapt to the new situation. Thus, it is necessary to explore their self-efficacy and self-regulated learning. The objective of this paper is twofold: 1) to describe the profiles of students' online learning self-efficacy and students' online self-regulated learning; and 2) to investigate the relationship between self-efficacy and self-regulated learning in online learning among university students during the COVID-19 pandemic. This quantitative study included a sample $(n=260)$ of university students enrolled in an accounting education study program. First, the study found that students exhibit a high level of online learning self-efficacy and online self-regulated learning. Second, the results of this study revealed a strong positive correlation between students' online self-efficacy and online self-regulated learning $(r=0.67, p<0.0005)$. This indicates that students' high levels of online self-efficacy are correlated with their high levels of online self-regulated learning.
\end{abstract}

Index Terms-Online learning, self-efficacy, self-regulated learning, university students.

\section{INTRODUCTION}

Coronavirus disease (COVID-19) impacts human life around the world, including education in Indonesia. As a result, the government of Indonesia through the Minister of Education and Culture launched Circular Letter No. 36962/ MPK.A/HK/2020 about Online Learning and Work from Home to Prevent the Spread of COVID-19. This was strengthened by the launch of Circular Letter No. 4 the Year 2020 about the Implementation of Education Policy in the Emergency of the Spread of COVID-19. It is believed that online learning is the best option to prevent the spread of COVID-19 in the education sector.

Online learning has some consequences for university students. They need to prepare themselves to adapt both physically and mentally to online learning facilities, the learning environment, and self-regulated learning. The recent study of Harahap et al. [1] revealed that university students still need to adapt and have good self-regulated learning during the pandemic, although their self-regulated learning is on the medium level.

The topic of self-regulated learning has received considerable attention. Zimmerman [2] pointed out that definitions of students' self-regulated learning involve three

Manuscript received June 22, 2021; revised July 17, 2021. This work was supported by Universitas Muhammadiyah Surakarta, PID-1640.

The autors are with the Faculty of Teacher Training and Education, Universitas Muhammadiyah Surakarta, Kartasura, Surakarta 57102, Indonesia (e-mail: titik.ulfatun@ums.ac.id,a210170040@student.ums.ac.id, and a210170060@student.ums.ac.id). features: their use of self-regulated learning strategies, their responsiveness to self-oriented feedback about learning effectiveness, and their interdependent motivational processes. In his major study, Zimmerman [2] also concluded that academic self-regulated learning emphasized how students select, organize, or create an advantageous learning environment for themselves and how they plan and control the form and amount of their instruction.

Zimmerman [2] mentioned that a key feature of self-regulated learning theories is that student learning and motivation are viewed as interrelated processes that cannot be fully understood separately from each other. Furthermore, Schunk (as cited in [2]) stated that self-efficacy perceptions among students are both a motivation to learn and a result of those efforts. This implies that self-efficacy is a well-studied indicator of students' motivation to self-regulate. Ultimately, having higher self-efficacy is expected to lead to better achievement. As Basith et al. [3] mentioned, self-efficacy is a predictor of academic achievement and has a positive relationship with it. Similarly, Namok [4] concluded that college students with a high level of self-perception obtain greater academic success.

Bandura [5] defined perceived self-efficacy as people's beliefs of their capacities to achieve specific levels of performance that have an impact on events in their lives. He added that self-efficacy beliefs influence how people feel, think, motivate themselves, and act. Furthermore, he mentioned that self-efficacy beliefs play an important role in the self-regulation of motivation.

A considerable amount of literature has been published on self-regulated learning and self-efficacy. Previous studies have reported a positive relationship between self-efficacy and self-regulated learning. Alegre [6] reported that academic self-efficacy and self-regulated learning had a positive, significant, and moderate relationship. Likewise, Fauzan [7] found that there was a positive relationship between self-efficacy and self-regulated learning. Pamungkas et al. [8] revealed that there was a positive and significant relationship between academic self-efficacy and self-directed learning, where the higher the level of self-efficacy, the greater the self-directed learning.

However, there has been little discussion of the relationship between self-efficacy and self-regulated learning in online learning among university students, especially during the COVID-19 pandemic. This study attempts to describe the profiles of students' online learning self-efficacy and online self-regulated learning. Then, this research aims to investigate the relationship between university students' online learning self-efficacy and online self-regulated learning during the COVID-19 pandemic. The hypothesis of this research is that there is a positive correlation between 
students' online learning self-efficacy and self-regulated learning. This study contributes to the growing area of online learning research by exploring the relationship between the self-efficacy and self-regulated learning of university students in online learning during the COVID-19 pandemic. Lecturers will be guided on what should be emphasized in online learning regarding students' self-efficacy and self-regulated learning, especially in terms of the online learning environment, time management, and task strategies. For university policymakers, the examination will shed light on the critical area of students' time management, especially regarding managing their schoolwork while they face distractions. Thus, new policies in this area may be needed.

\section{METHODS}

This research applies a quantitative method with a correlational approach, which has the broad goal of clarifying fundamental phenomena by identifying relationships between variables [9]. This study uses a survey research design, which is "well suited to descriptive studies, or where researchers want to look at relationships between variables occurring in particular real-life contexts" [10].

The target population of this research was students enrolled in an accounting education study program in a university in Indonesia. The total population is 714 students, which consists of 253 students in the class of 2017, 187 students in the class of 2018, 190 students in the class of 2019 , and 84 students in the class of 2020. The study used simple random sampling. The sample consisted of 260 students as participants, which were drawn according to [11] with a $95 \%$ confidence level and a 5\% confidence interval.

Two questionnaires were used in this study. The design of the questionnaires was adapted from previous studies. First, the questionnaire to measure students' online learning self-efficacy is the Online Learning Self-Efficacy Scale (OLSES) adapted from [12]. This scale consists of 22 items and three subscales: learning in the online environment, time management, and technology use. The questionnaire is answered using a 6-point scale ranging from poor to expert. In [12], it is mentioned that the Cronbach's alpha of the internal consistency reliability of the scale ranged from 0.843 to 0.890 , indicating high internal consistency according to [11].

Second, the questionnaire to measure online self-regulated learning is the Online Self-Regulated Learning Questionnaire (OSLQ) adapted from [13]. This questionnaire consists of 24 items and six subscales: goal setting, environment structuring, task strategies, time management, help-seeking, and self-evaluation. The questionnaire is answered using a 5-point scale from strongly disagree to strongly agree. Barnard et al. [13] reported that reliability coefficients ranged from 0.87 to 0.96 , which indicated high to very high reliability.

In addition to reliability, both questionnaires confirmed validity. However, in this study, the researchers applied a modified OLSES questionnaire with 20 items and a 5-point scale ranging from no confidence to high confidence. Thus, reliability and validity tests were applied for OLSES. The researchers also applied reliability and validity tests to OSLQ.
35 students were recruited for these tests. The results showed that Cronbach's alpha for OLSES is 0.900 and for OSLQ 0.916 . The validity tests revealed that there was one item that was not valid for OLSES and one item that was not valid for OSLQ. As a result, there were 19 items in OLSES and 23 items in OSLQ.

The questionnaires were collected from the participants online from December 2020 to February 2021. The data collected were analyzed using the Statistical Package for the Social Sciences (SPSS). Before performing the correlation analysis, it is necessary to assess normality, linearity, and homoscedasticity. The normality was checked by inspecting the results of the Kolmogorov-Smirnov statistic, histograms, and the normal probability plots labeled as normal Q-Q plot, while a scatterplot was necessary to check for violations of the assumptions of linearity and homoscedasticity [14]. The results of these checks are shown in the results and discussions sections. Then, Pearson's product-moment was performed to see the correlation between students' online self-efficacy and self-regulated learning. Table I shows the interpretation of r-value (Cohen as cited in [14]):

TABLE I: INTERPRETATION OF $R$-VALUE

\begin{tabular}{ccc}
\hline \multicolumn{3}{c}{ TABLE I: INTERPRETATION OF $R$-VALUE } \\
\hline \hline No. & $r$-value & Interpretation \\
\hline 1. & $r=0.10$ to 0.29 & Small \\
2. & $r=0.30$ to 0.49 & Medium \\
3. & $r=0.50$ to 1.0 & Large \\
\hline \hline
\end{tabular}

\section{RESULTS}

This survey involved 260 students with different demographic backgrounds (see Table II). The respondents consisted of 99 students $(38.1 \%)$ from the class of 2017,67 students $(25.8 \%)$ from the class of 2018,49 students $(18.8 \%)$ from the class of 2019 , and 45 students $(17.3 \%)$ from the class of 2020. More than three-quarters of the respondents were female $(80.8 \%)$. Regarding students' age, the majority of the students $(60.8 \%)$ were between the ages of 20 and 21 . 69 students $(26.5 \%)$ were $18-19$ years old and 33 students (12.7\%) were $22-23$ years old.

TABLE II: DEMOGRAPHIC BACKGROUND OF STUDENTS

\begin{tabular}{ccc}
\hline \multicolumn{1}{c}{ Attributes } & N (260) & Percentage $(\%)$ \\
\hline Class of & & 38.1 \\
2017 & 99 & 25.8 \\
2018 & 67 & 18.8 \\
2019 & 49 & 17.3 \\
2020 & 45 & \\
Gender & & 19.2 \\
Male & 50 & 80.8 \\
Female & 210 & \\
Age & & 26.5 \\
18-19 years old & 69 & 60.8 \\
20-21 years old & 158 & 12.7 \\
22-23 years old & 33 & \\
\hline \hline
\end{tabular}

Before examining the relationship between students' online self-efficacy and online self-regulated learning, it is necessary to determine the level of students' online self-efficacy and self-regulated learning. For this, the researchers employed descriptive statistics such as mean and standard deviation. First, there were 19 items in OLSES, which consisted of three subscales: learning in the online environment, time management, and technology use. OLSES 
consists of a 5-point scale anchored $1=$ no confidence, $2=$ low confidence, $3=$ neutral, $4=$ confidence, and $5=$ high confidence. Table III shows the mean score and standard deviation of each item of OLSES.

TABLE III: THE MEAN SCORE AND STANDARD DEVIATION OF OLSES

\begin{tabular}{|c|c|c|c|c|c|}
\hline Item/Subscale & $\overline{\mathrm{M}}$ & SD & Item/Subscale & $\overline{\mathrm{M}}$ & SD \\
\hline \multicolumn{3}{|c|}{ Learning in the Online Environment } & \multicolumn{3}{|c|}{ Time Management } \\
\hline 2 & 3.68 & 0.822 & 5 & 3.57 & 0.930 \\
\hline 4 & 3.36 & 0.892 & 6 & 4.02 & 0.896 \\
\hline 7 & 3.77 & 0.887 & 13 & 4.22 & 0.808 \\
\hline 8 & 3.46 & 0.960 & 16 & 3.32 & 1.041 \\
\hline 9 & 3.49 & 0.973 & 17 & 3.73 & 0.832 \\
\hline 12 & 3.86 & 0.803 & Technology Use & & \\
\hline 14 & 3.94 & 0.888 & 1 & 3.38 & 0.831 \\
\hline 15 & 4.31 & 0.776 & 3 & 4.44 & 0.735 \\
\hline 18 & 3.32 & 0.951 & 10 & 3.82 & 0.892 \\
\hline \multirow[t]{2}{*}{19} & 3.81 & 0.851 & 11 & 3.99 & 0.820 \\
\hline & & & Total OLSES & 3.79 & 0.867 \\
\hline
\end{tabular}

Note: $N=260, M=$ Mean, $S D=$ Standard deviation.

The highest mean score was related to technology use, that is item number 3 "Submit assignments to an online dropbox" $(M=4.44, S D=0.735)$. On the contrary, the lowest mean scores were for item number 18 "Use the library's online resources efficiently" $(M=3.32, S D=0.951)$, which belongs to learning in the online environment, and item number 16 "Focus on schoolwork when faced with distractions" ( $M=$ $3.32, \mathrm{SD}=1.041)$, which belongs to time management. The mean total OLSES score was $3.79(S D=0.867)$. This average score fell between "neutral" and "confidence" in the statements of OLSES.

The mean score ideal and standard deviation ideal were used to categorize the level. The mean score ideal was drawn from dividing the sum of maximum score ideal (19 items multiplied by 5) and minimum score ideal (19 items multiplied by 1) by two. The standard deviation ideal was drawn from dividing the difference of maximum score ideal and minimum score ideal by two. The categorization is divided into three levels: low, medium, and high. The mean score ideal and standard deviation ideal were consulted for the categorization formula (see Table IV). The frequency and percentage were inputted afterward.

TABLE IV: CATEGORIZATION FORMULA

\begin{tabular}{ll}
\hline \multicolumn{1}{c}{ Interval Score } & \multicolumn{1}{c}{ Category } \\
\hline$X<\mathrm{Mi}-1 \mathrm{SDi}$ & Low \\
$\mathrm{Mi}-1 \mathrm{SDi} \leq X<\mathrm{Mi}+1 \mathrm{SDi}$ & Medium \\
$\mathrm{Mi}+1 \mathrm{SDi} \leq X$ & High \\
\hline \hline
\end{tabular}

Note: $X=$ Actual score of each respondent, $\mathrm{M}=$ Mean ideal, $\mathrm{SD}=$ Standard deviation ideal, Source: [15].

Based on the formula, the categorization of respondents' online learning self-efficacy score was less than $44(X<44)$ for low level, greater than or equal to 44 but less than 70 (44 $\leq X<70$ ) for medium level, and greater than or equal to 70 $(70 \leq X)$ for high level. For example, the total OLSES score of Respondent 1 was 76 . Based on the formula, Respondent 1 belongs to the high level. Table $\mathrm{V}$ reveals that more than half of the students $(55 \%)$ belong to the high level. Only two students $(0.77 \%)$ belong to the low level.

Second, there were 23 items in OSLQ, which consisted of six subscales: goal setting, environmental structuring, task strategies, time management, help-seeking, and self-evaluation. OSLQ consists of a 5-point scale anchored 1
$=$ strongly disagree, $2=$ disagree, $3=$ neutral, $4=$ agree, and 5 $=$ strongly agree. Table VI shows the mean score and standard deviation of each item of OSLQ.

TABLE V: CATEGORIZATION OF STUDENTS' ONLINE LEARNING SELF-EFFICACY

\begin{tabular}{|c|c|c|c|}
\hline Interval Score & Category & Frequency & Percentage $(\%)$ \\
\hline$X<44$ & Low & 2 & 0.77 \\
\hline $44 \leq X<70$ & Medium & 115 & 44.23 \\
\hline $70 \leq X$ & High & 143 & 55.00 \\
\hline Total & & 260 & 100 \\
\hline
\end{tabular}

TABLE VI: THE MEAN SCORE AND STANDARD DEVIATION OF OSLQ

\begin{tabular}{|c|c|c|c|c|c|}
\hline Item/Subscale & $\mathrm{M}$ & SD & Item/Subscale & $\bar{M}$ & SD \\
\hline Goal Setting & \multicolumn{5}{|c|}{ Time Management } \\
\hline 1 & 3.70 & 0.808 & 14 & 3.55 & 0.762 \\
\hline 2 & 3.69 & 0.759 & 15 & 3.53 & 0.812 \\
\hline 3 & 3.77 & 0.833 & Help Seeking & & \\
\hline 4 & 3.80 & 0.784 & 16 & 3.87 & 0.922 \\
\hline 5 & 3.77 & 0.854 & 17 & 4.05 & 0.808 \\
\hline \multicolumn{3}{|c|}{ Environmental Structuring } & 18 & 3.86 & 0.932 \\
\hline 6 & 4.22 & 0.764 & 19 & 3.57 & 0.896 \\
\hline 7 & 4.02 & 0.887 & \multicolumn{3}{|l|}{ Self-Evaluation } \\
\hline 8 & 4.03 & 0.795 & 20 & 3.60 & 0.876 \\
\hline 9 & 3.71 & 0.930 & 21 & 3.73 & 0.828 \\
\hline \multicolumn{3}{|l|}{ Task Strategies } & 22 & 3.56 & 0.892 \\
\hline 10 & 3.65 & 0.885 & 23 & 3.84 & 0.890 \\
\hline 11 & 3.25 & 0.995 & Total OSLQ & 3.70 & 0.847 \\
\hline 12 & 3.24 & 0.814 & & & \\
\hline 13 & 3.40 & 0.839 & & & \\
\hline
\end{tabular}

Note: $N=260, M \quad=$ Mean, $S D=$ Standard deviation.

The highest mean score was related to environmental structuring, that is item number 6 "I choose the location where I study to avoid too much distraction" $(M=4.22, S D=$ 0.764). On the contrary, the lowest mean score was for item number 12 "I prepare my questions before joining the chat room and discussion" $(M=3.24, S D=0.814)$, which belongs to task strategies. The mean total OLSES score was 3.70 ( $S D$ $=0.847)$. This average score fell between "neutral" and "agree" in the statements of OSLQ.

The mean score ideal and standard deviation ideal were used to categorize the level. The mean score ideal was drawn from dividing the sum of maximum score ideal (23 items multiplied by 5) and minimum score ideal (23 items multiplied by 1) by two. The standard deviation ideal was drawn from dividing the difference of maximum score ideal and minimum score ideal by two. The categorization also is divided into three levels: low, medium, and high. The mean score ideal and standard deviation ideal were consulted for the categorization formula (see Table IV). The frequency and percentage were inputted afterward.

TABLE VII: CATEGORIZATION OF STUDENTS’ ONLINE SELF-REGULATED LEARNING

\begin{tabular}{llcc}
\hline \multicolumn{1}{c}{ Interval Score } & Category & Frequency & Percentage (\%) \\
\hline $\mathrm{X}<54$ & Low & 1 & 0.38 \\
$54 \leq \mathrm{X}<84$ & Medium & 109 & 41.92 \\
$84 \leq \mathrm{X}$ & High & 150 & 57.70 \\
Total & & 260 & 100 \\
\hline \hline
\end{tabular}

Based on the formula, the categorization of respondents' online self-regulated learning score was less than $54(X<54)$ for low level, greater than or equal to 54 but less than 84 (54 $\leq X<84$ ) for medium level, and greater than or equal to 84 $(84 \leq X)$ for high level. For example, the total OSLQ score of Respondent 2 was 75 . It can be seen that Respondent 2 belongs to the medium level. Table VII shows that the 
majority of students $(57.70 \%)$ belong to the high level. Only one student $(0.38 \%)$ belongs to the low level.

Before performing the correlation analysis, the results of the Kolmogorov-Smirnov statistic (see Table VIII and Table IX), histograms (see Fig. 1 and Fig. 3), and normal Q-Q plot (see Fig. 2 and Fig. 4) for assessing normality and scatterplot for checking linearity and homoscedasticity are showed.

TABLE VIII: THE RESULTS OF THE KOLMOGOROV-SMIRNOV STATISTIC FOR TOTAL OLSES

\begin{tabular}{lr|c|c|r|c|c}
\hline \hline & \multicolumn{3}{c}{ Kolmogorov-Smirnov } & \multicolumn{3}{c}{ Shapiro-Wilk } \\
& Statistic & df & Sig. & Statistic & df & Sig. \\
\hline Total OLSES & 0.070 & 260 & 0.004 & 0.985 & 260 & 0.008 \\
\hline \hline
\end{tabular}

a. Lilliefors significance correction

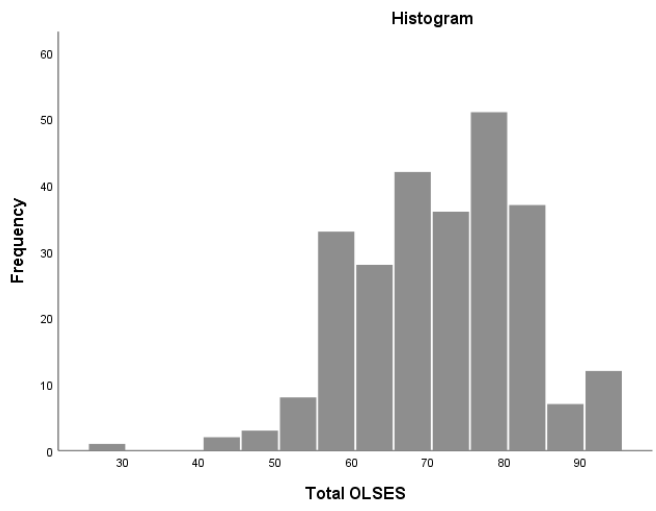

Fig. 1. Histogram of total OLSES.

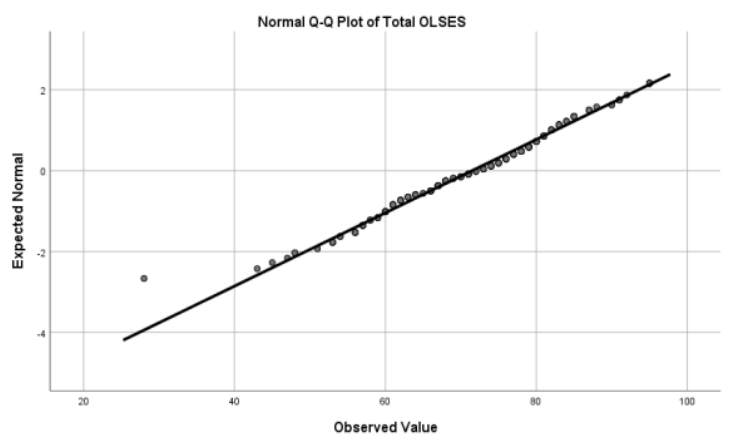

Fig. 2. Normal Q-Q plots for total OLSES.

TABLE IX: THE RESUlTS OF THE KOLMOGOROV-SMIRNOV STATISTIC FOR TOTAL OSLQ

\begin{tabular}{lr|c|c|c|c|c}
\hline \hline & \multicolumn{3}{c}{ Kolmogorov-Smirnov } & \multicolumn{3}{c}{ Shapiro-Wilk } \\
& Statistic & df & Sig. & Statistic & df & Sig. \\
\hline Total OSLQ & 0.063 & 260 & 0.014 & 0.991 & 260 & 0.096 \\
\hline \hline
\end{tabular}

The results of the Kolmogorov-Smirnov statistic show that the Sig. value is 0.004 for total OLSES and 0.014 for total OSLQ, indicating violations of the assumption of normality. [14] said that in bigger samples, this is quite common. The actual shape of the distributions can be seen in histograms. Both histograms show reasonably normal distributions. These are supported by the normal probability plots, where reasonably straight lines indicate normal distributions.

Fig. 5 indicates a linear relationship, so it is suitable for correlation analysis using a Pearson product-moment correlation for the two variables (students' online self-efficacy and online self-regulated learning). Additionally, the scatterplot shows a fairly even cigar shape along its length, suggesting no violation of the assumptions of homoscedasticity.

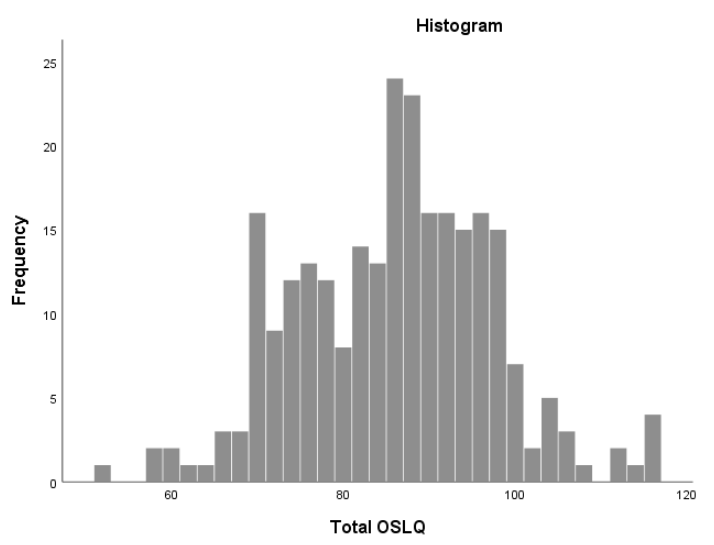

Fig. 3. Histogram of total OSLQ.

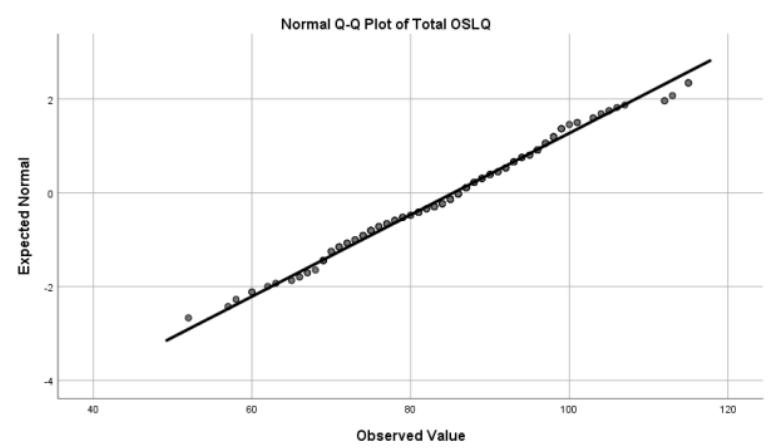

Fig. 4. Normal Q-Q plot of total OSLQ.

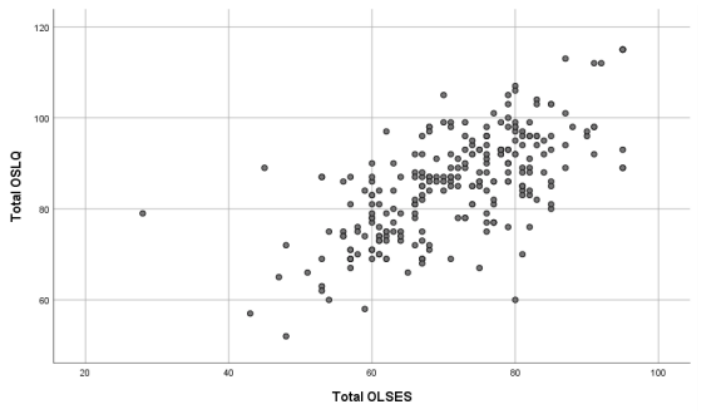

Fig. 5. Scatterplot of total OLSES and total OSLQ.

TABLE X: PEARSON PRODUCT-MOMENT CORRELATIONS BETWEEN STUDENTS' ONLINE SELF-EFFICACY AND SELF-REGULATED LEARNING

\begin{tabular}{clrr}
\hline \hline & \multicolumn{1}{c}{ Scale } & OLSES & \multicolumn{1}{c}{ OSLQ } \\
\hline OLSES & Pearson Correlation & 1 & $0.668^{* *}$ \\
& Sig. (two-tailed) & & 0.000 \\
& N & 260 & 260 \\
OSLQ & Pearson Correlation & $0.668^{* * *}$ & 1 \\
& Sig. (two-tailed) & 0.000 & \\
& $\mathrm{~N}$ & 260 & 260 \\
\hline \hline
\end{tabular}

**. Correlation is significant at the 0.01 level (two-tailed).

The relationship between students' online self-efficacy (as measured by OLSES) and online self-regulated learning (as measured by OSLQ) was examined by applying Pearson's product-moment correlation coefficient (r). Preliminary analyses were carried out to ensure that the assumptions of normality, linearity, and homoscedasticity were not violated. There was a strong positive correlation between the two variables $(r=0.67, n=260, p<0.0005)$, with high levels of online self-efficacy associated with high levels of online self-regulated learning. Table $\mathrm{X}$ presents the correlations between the two variables. 


\section{DiscussIONS}

A possible explanation for the highest score appearing for technology use (see Table III) is that students are familiar with the technology itself, including that used for learning, so they are confident when submitting tasks to an online dropbox. However, students may not be familiar with the online learning environment, especially using online resources such as an online library. They might think that the materials their lecturers provide are enough, so they do not need to find other sources through an online library. Other possible explanations are a limited number of online libraries, students not knowing how to use them, or sources that are not relevant to their studies. Moreover, students seem to struggle with time management; they cannot focus on their schoolwork due to the problems that they face. This might indicate that distractions affect their self-efficacy in online learning. These two issues need to be solved.

The two aforementioned results concerning the lowest scores for self-efficacy, "Use the library's online resources efficiently" and "Focus on schoolwork when faced with distractions," are consistent with the findings of [12]. These authors proposed that instructors should provide instruction for students to utilize online libraries efficiently. Regarding schoolwork and distractions, they argued that universities should take this problem into account.

The COVID-19 pandemic has increased the number of students learning from home, where they might face problems such as noise and lack of internet signal. Students' difficulties with internet access and digital gadgets during remote learning were linked to decreased distance learning proficiency [16]. As a result, they need to manage their learning environment at home, beginning with selecting a study location free of distractions (see Table IV). In terms of task strategies, specifically in terms of "preparing questions before joining the chat room and discussion," although the students' answers tended to be neutral, the score was the lowest of all the items. This may be due to a lack of time to read the material first, which leads to a lack of understanding of the course material, resulting in students not preparing questions before joining an online class. Instructors/lecturers could implement a flipped classroom so that the students complete readings first while they have questions on their minds, which will be discussed in the classroom.

Despite these lowest scores, the students' overall self-reported self-efficacy and self-regulated learning in online learning were categorized as high (see Table $\mathrm{V}$ and Table VII). A possible explanation for this is that online learning experience and knowledge affect self-efficacy in online learning, as [17] and [12] mentioned. [18] found that students with more internet experience reported a higher level of self-efficacy. Current university students have generally been around technology for a long time. In terms of online learning, many have been doing it since March 2020. Moreover, [4] and [19] revealed that higher levels of technology self-efficacy were associated with higher final grades. A high level of self-regulated learning was mostly achieved through environment structuring. [20] mentioned that the educational environment is a factor affecting self-regulated learning. Furthermore, [21] stated that grade performance is highly connected to time and study environment, as well as effort regulation. Another possible explanation for this is high self-efficacy and motivation, which are correlated to high self-regulated learning. However, one needs to be cautious about the factors underlying these high levels of self-efficacy and self-regulated learning.

This study confirms that students' self-efficacy is associated with their self-regulated learning, specifically in terms of online learning. This finding is in agreement with those of [6], [7], and [8], which showed that the two variables were correlated. The first two studies mostly focus on classroom-based learning, while the last study and this study put more emphasis on the online learning context.

The result also agrees with the findings of other studies [22], [23]. Similar to this study, the Pearson's correlation analysis in [22] showed a positive and strong relationship, while [23] described a positive direction with a medium strength correlation.

The observed correlation between students' online learning self-efficacy and self-regulated learning might be explained in this way. As mentioned by [5], self-efficacy beliefs are important in the self-regulation of motivation, where people create beliefs about their capabilities. It can be implied that one of the motivations is the motivation to learn. Motivation and student learning are crucial aspects of self-regulated learning that are interrelated [2]. Thus, when people have high self-efficacy, it will correlate to high self-regulated learning. In this case, a high level of self-efficacy correlated with a high level of self-regulated learning in online learning during the COVID-19 pandemic.

This study has several limitations. First, it is based on the students' self-reported assessments of their self-efficacy and self-regulated learning in online learning. This could be related to bias in the questionnaire responses. Applying other methods such as interviews and/or observation might reduce bias. Second, this research only focuses on the correlation between two variables, which indicates the relationship between those two variables. The correlation itself does not indicate that one variable causes the other. Third, this study investigated only the total OLSES and OSLQ scores, not those for the subscales. Future work should be done to investigate the subscales of both OLSES and OSLQ.

\section{CONCLUSION}

The objectives of this study were to describe the profiles of students' online learning self-efficacy and online self-regulated learning and to investigate the relationship between those two variables. This study found that students have a high level of self-efficacy and self-regulated learning in online learning. The highest mean OLSES score was related to technology use, while the lowest concerned learning in the online environment and time management. The highest mean OSLQ score was about environmental structuring, while the lowest pertained to task strategies. Furthermore, the results of the investigation showed that there was a strong and positive relationship between students' online learning self-efficacy and online self-regulated learning. The results of this research support previous studies. The findings may help us understand the 
importance of instructional strategies to maintain students' online learning self-efficacy and self-regulated learning during the COVID-19 pandemic, such as video demonstrations, collaborative learning, discussions, and flipped classroom.

\section{CONFLICT OF INTEREST}

The authors declare no conflict of interest.

\section{AUTHOR CONTRIBUTIONS}

Titik Ulfatun prepared the research instrument and wrote the paper; Fitri Septiyanti helped in collecting the data and literature review; Aprilia Garia Lesmana helped in collecting the data.

\section{ACKNOWLEDGMENT}

The authors would like to thank the respondents for participating in this study. We would also like to thank the academic members of the Faculty of Teacher Training and Education at the Universitas Muhammadiyah Surakarta for their support.

\section{REFERENCES}

[1] A. C. P. Harahap and S. R. Harahap, "Covid 19: Self regulated learning mahasiswa," J. Pendidik. dan Konseling, vol. 10, no. 1, pp. 36-42, 2020.

[2] B. J. Zimmerman, "Self-regulated learning and academic achievement: An overview," Educ. Psychol., vol. 25, no. 1, pp. 3-17, 1990, doi: http://dx.doi.org/10.1207/s15326985ep2501_2.

[3] A. Basith, A. Syahputra, and M. A. Ichwanto, "Academic self-efficacy as predictor of academic achievement," JPI (Jurnal Pendidik. Indones. vol. 9, no. 1, pp. 163-170, 2020, doi: 10.23887/jpi-undiksha.v9i1.24403.

[4] C. Namok, "Self-efficacy and self-concept as predictors of college students' academic performance," Psychol. Sch., vol. 42, no. 2, pp. 197-205, 2005.

[5] A. Bandura, Self-efficacy, vol. 4. 1994.

[6] A. A. Alegre, "Academic self-efficacy, self-regulated learning and academic performance in first-year university students ," Propósitos y Represent., vol. 2, no. 1, pp. 79-120, 2014, doi: 10.20511/pyr2014.v2n1.54.

[7] A. Fauzan, "Hubungan self efficacy dengan kemandirian belajar pada mahasiswa Pendidikan Akuntansi pada prodi Pendidikan Ekonomi angkatan 2013 Fakultas Ekonomi Universitas Negeri Jakarta," Universitas Negeri Jakarta, 2016.

[8] S. W. Pamungkas and E. S. Indrawati, "Hubungan antara efikasi diri akademik dengan self-directed learning pada mahasiswa program studi PGSD Universitas terbuka di wilayah Kabupaten Demak," J. Empati, vol. 6, no. 1, pp. 401-406, 2017.

[9] J. R. Fraenkel, N. E. Wallen, and H. H. Hyun, How to Design and Evaluate Research in Education, New York: McGraw-Hill, 2012.

[10] D. Muijs, Doing Quantitative Research in Education with SPSS, London: SAGE Publications, 2004.

[11] L. Cohen, L. Manion, and K. Morrison, Research Methods in Education, Sixth edit. Oxon: Routledge, 2007.

[12] W. A. Zimmerman and J. M. Kulikowich, "Online learning self-efficacy in students with and without online learning experience," Am. J. Distance Educ., vol. 30, no. 3, pp. 180-191, 2016, doi: 10.1080/08923647.2016.1193801.

[13] L. Barnard, W. Y. Lan, Y. M. To, V. O. Paton, and S.-L. Lai, "Measuring self-regulation in online and blended learning environments," Internet High. Educ., vol. 12, no. 1, pp. 1-6, 2009, doi: 10.1016/j.iheduc.2008.10.005.
[14] J. Pallant, SPSS Survival Manual: A Step by Step Guide to Data Analysis Using SPSS, Crows Nest: Allen \& Unwin, 2011.

[15] S. Azwar, Penyusunan Skala Psikologi, Edisi II. Yogyakarta: Pustaka Pelajar, 2019.

[16] V. S. Katz, A. B. Jordan, and K. Ognyanova, "Digital inequality, faculty communication, and remote learning experiences during the COVID-19 pandemic: A survey of U.S. undergraduates," PLoS One, vol. 16, no. 2, pp. 1-16, 2021, doi: 10.1371/journal.pone.0246641.

[17] C. Peechapol, J. Na-songkhla, S. Sujiva, and A. Luangsodsai, "An exploration of factors influencing self-efficacy in online learning: A systematic review," Int. J. Emerg. Technol. Learn., vol. 13, no. 9, pp. 64-86, 2018, doi: https://doi.org/10.3991/ijet.v13i09.8351.

[18] B. Samruayruen, J. Enriquez, O. Natakuatoong, and K. Samruayruen, "Self-regulated learning: A key of successful learner in online learning environments in Thailand," J. Educ. Comput. Res., vol. 48, no. 1, pp 45-69, 2013, doi: http://dx.doi.org/10.2190/EC.48.1.c.

[19] C.-H. Wang, D. M. Shannon, and M. E. Ross, "Students' characteristics, self-regulated learning, technology self-efficacy, and course outcomes in online learning," Distance Educ., vol. 34, no. 3, pp. 302-323, 2013, doi: 10.1080/01587919.2013.835779.

[20] Z. Jouhari, F. Haghani, and T. Changiz, "Factors affecting self-regulated learning in medical students: a qualitative study," Med. Educ. Online, vol. 20, no. 28694, pp. 1-8, 2015, doi: 10.3402/meo.v20.28694

[21] M. Puzziferro, "Online technologies self-efficacy and self-regulated learning as predictors of final grade and satisfaction in college-level online courses," Am. J. Distance Educ., vol. 22, no. 2, pp. 72-89, 2008 , doi: 10.1080/08923640802039024.

[22] Z. An, C. Wang, S. Li, Z. Gan, and H. Li, "Technology-assisted self-regulated English language learning: Associations with English language self-efficacy, English enjoyment, and learning outcomes," Front. Psychol., vol. 11, no. January, pp. 1-14, 2021, doi: 10.3389/fpsyg.2020.558466.

[23] D. Lee, S. L. Watson, and W. R. Watson, "The relationships between self-efficacy, task value, and self-regulated learning strategies in Massive Open Online Courses," Int. Rev. Res. Open Distrib. Learn., vol. $21, \quad$ no. $1, \quad$ pp. 23-39, 2021, https://doi.org/10.19173/irrodl.v20i5.4389.

Copyright $\odot 2021$ by the authors. This is an open access article distributed under the Creative Commons Attribution License which permits unrestricted use, distribution, and reproduction in any medium, provided the original work is properly cited (CC BY 4.0)

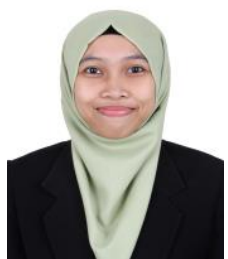

Titik Ulfatun is a lecturer at the Faculty of Teacher Training and Education, Universitas Muhammadiyah Surakarta, Indonesia. She received the B.Ed. degree from Universitas Negeri Yogyakarta, Yogyakarta Indonesia in 2016. After graduation, she worked as a teacher in a private vocational high school (2016-2017). She continued her studies and received the M.Ed. degree in 2019 from Hiroshima University,

Hiroshima, Japan

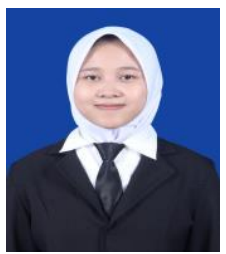

Fitri Septiyanti is a student at the Faculty of Teacher Training and Education, Universitas Muhammadiyah Surakarta, Indonesia. She is a final-year student.

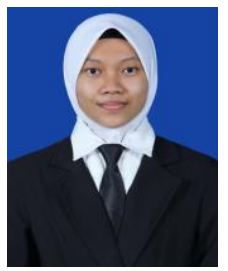

Aprilia Garia Lesmana is a student at the Faculty of Teacher Training and Education, Universitas Muhammadiyah Surakarta, Indonesia. She is in her final year of studies. 